УДК 669.245

МЕХАНИЧЕСКИЕ СВОЙСТВА НИКЕЛЬКРЕМНИЕВЫХ СПЛАВОВ

\author{
A.A. Лаптев, аспирант \\ М.Ю. Беломытцев, д.т.н., профессор \\ А.И. Лаптев, д.т.н, вед.н.с.
}

Национальный исследовательский технологический университет «МИСиС» (Москва, Россия)

Аннотация. Никелькремниевые сплавы находят применение при изготовлении жаростойких покрытий. Однако, в связи с тем, что получение компактных образцов представляет значительные трудности, в литературе недостаточно данных по их механическим свойствам. В представленной работе разработана технология изготовления никелькремниевых сплавов для проведения механических испытаний, заключающаяся в плавлении сплава под давлением, охлаждении сплава под давлением и снижении давления. Изготовлены шлифы образцов с различным химическим составом, проведено изучение их структуры и микротвердости. В результате изучения установлено, что при увеличении содержания кремния до 30 - 40 \% микротвердость никелькремниевых сплавов снижается до 5,5 - 6,0 ГПа, при дальнейшем увеличении содержания кремния микротвердость значительно повышается, что связано с появлением в структуре фаз $\mathrm{NiSi} 2$ и $\mathrm{Si}$, имеющих высокие значения микротвердости.

Ключевые слова: микротвердость, микроструктура, никелькремниевые сплавы, шлифы, давление, сплавление.

\title{
E-MAIL: laptev85@mail.ru
}

Сплавы никеля с кремнием широко распространены в промышленности в качестве жаростойких покрытий [1], связок алмазных композиционных материалов [2]. Однако их механические свойства изучены недостаточно полно. Это связано с тем, что сплавы с большим содержанием кремния обладают повышенной хрупкостью, имеют большое количество трещин и представляют значительные трудности при изготовлении стандартных образцов для механических испытаний. Особенностью взаимодействия никеля с кремнием является большое количество образующихся промежуточных фаз. Диаграмма состояния системы никелькремний представлена на рис. 1 [3-4]. Она состоит из двух твердых растворов $\mathrm{Si}$ в $\mathrm{Ni}$ и $\mathrm{Ni}$ в $\mathrm{Si}$, жидкой

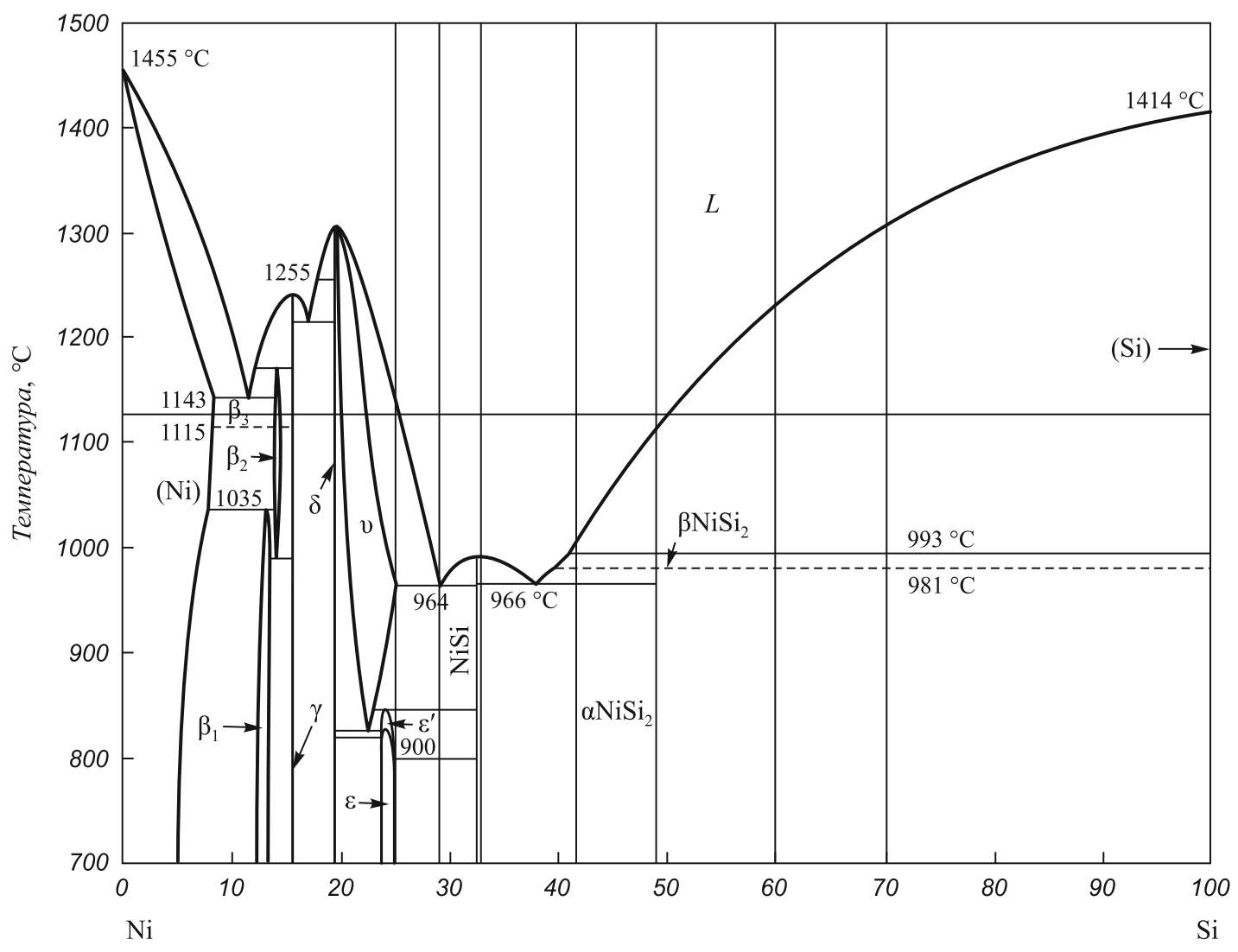

Рис. 1. Диаграмма состояния $\mathrm{Ni}-\mathrm{Si}$ 
фазы и 11 интерметаллидных фаз: $\mathrm{Ni}_{3} \mathrm{Si}\left(\beta_{1}\right), \mathrm{Ni}_{3} \mathrm{Si}\left(\beta_{2}\right)$, $\mathrm{Ni}_{3} \mathrm{Si}\left(\beta_{3}\right), \quad \mathrm{Ni}_{2} \mathrm{Si}(\theta), \quad \mathrm{Ni}_{3} \mathrm{Si}_{2}\left(\varepsilon_{L}\right), \quad \mathrm{Ni}_{3} \mathrm{Si}_{2}\left(\varepsilon_{H}\right), \quad \mathrm{Ni}_{5} \mathrm{Si}_{2}(\gamma)$, $\mathrm{Ni}_{2} \mathrm{Si}(\delta), \mathrm{NiSi} \mathrm{NiSi}_{2}(\alpha), \mathrm{NiSi}_{2}(\beta)$. Фазы $\mathrm{Ni}_{5} \mathrm{Si}_{2}, \mathrm{Ni}_{2} \mathrm{Si}$ и $\mathrm{NiSi}$ плавятся конгруэнтно при 1282,1318 и $992{ }^{\circ} \mathrm{C}$ соответственно; $\mathrm{Ni}_{3} \mathrm{Si}$ и $\mathrm{NiSi}_{2}$ - инконгруэнтно при 1165 и $1125{ }^{\circ} \mathrm{C}$ соответственно; $\mathrm{Ni}_{3} \mathrm{Si}_{2}$ разлагается, не плавясь, при $845^{\circ} \mathrm{C}$.

Некоторые свойства силицидов никеля приведены в табл. $1[5-6]$.

Изучение термодинамических свойств расплавов, проведенное в работе [4], свидетельствует о сильном химическом взаимодействии в расплаве никель-кремний.

Целью настоящей работы являлось изучение механических свойств сплавов системы никель-кремний.

В процессе проведения эксперимента были использованы следующие основные материалы:
- электролитический никель марки Н0;

- полупроводниковый кремний чистотой 99,99 \%.

Никелькремниевые сплавы готовили плавлением электролитического никеля и полупроводникового кремния в вакуумной индукционной печи фирмы LEYBOLD-HERAEUS мощностью 40 кВт. Использовали алундовые тигли. При изготовлении сплавов было отмечено, что сплавы, содержащие 60, 70 и 100 \% $\mathrm{Si}$ имели «отрицательную» усадочную раковину. Это свидетельствует о том, что кристаллизация этих сплавов происходила с увеличением удельного объема. На рис. 1 вертикальными линиями обозначены составы сплавов, изучаемых в настоящей работе. Составы изготовленных сплавов и результаты их рентгенофазового анализа представлены в табл. 2. Проведенный рентгенофазовый анализ приготовленных сплавов по-

Свойства силицидов никеля [5 - 6]

Т а бл и ц а 1

\begin{tabular}{|c|c|c|c|c|c|c|c|c|}
\hline Фаза & Сингония & $\begin{array}{c}\text { Пространственная } \\
\text { группа }\end{array}$ & $\begin{array}{c}\text { Структура } \\
\text { фаз }\end{array}$ & $\begin{array}{c}\text { Плотность, } \\
\Gamma / \mathrm{cm}^{3}\end{array}$ & $\begin{array}{l}\text { K.т.p. } \\
10^{-6} \mathrm{~K}^{-1}\end{array}$ & $\begin{array}{c}\text { Прочность } \\
\text { на растяже- } \\
\text { ние, МПа }\end{array}$ & $\begin{array}{c}\text { Прочность } \\
\text { на сжатие, } \\
\text { МПа }\end{array}$ & $\begin{array}{c}\text { Микро- } \\
\text { твердость, } \\
\text { ГПа } \\
\end{array}$ \\
\hline $\mathrm{Ni}_{3} \mathrm{Si}$ & Кубическая & $O_{h}^{1}-P m 3 m$ & $\mathrm{Cu}_{3} \mathrm{Au}$ & 7,86 & 11,5 & - & - & 4,0 \\
\hline $\mathrm{Ni}_{5} \mathrm{Si}_{2}$ & Тригональная & - & $\mathrm{Ni}_{5} \mathrm{Si}_{2}$ & - & - & - & - & - \\
\hline$\theta-\mathrm{Ni}_{2} \mathrm{Si}$ & Гексагональная & $D_{6 h}^{4}-P 6_{3} / m m c$ & $\mathrm{Ni}_{2} \mathrm{In}$ & 7,91 & 17,5 & 6,0 & 316 & 4,4 \\
\hline$\delta-\mathrm{Ni}_{2} \mathrm{Si}$ & Ромбическая & $D_{2 h}^{16}-P n m a$ & $\delta-\mathrm{Ni}_{2} \mathrm{Si}$ & 7,41 & - & - & - & - \\
\hline $\mathrm{Ni}_{3} \mathrm{Si}_{2}$ & Ромбическая & $C_{2 v}^{2}-C m c 2_{1}$ & $\mathrm{Ni}_{3} \mathrm{Si}_{2}$ & 6,74 & - & - & - & - \\
\hline $\mathrm{NiSi}$ & Ромбическая & $D_{2 h}^{16}-P n m a$ & $\mathrm{MnP}$ & 5,93 & - & 6,0 & 158 & 4,0 \\
\hline $\mathrm{Ni}_{1,04} \mathrm{Si}_{1,93}$ & Кубическая & $O_{h}^{5}-F m 3 m$ & $\mathrm{CaF}_{2}$ & 4,84 & 12,1 & - & - & 10,2 \\
\hline
\end{tabular}

Та бли ц а 2

Химические и фазовые составы никелькремниевых сплавов

\begin{tabular}{|c|c|c|c|c|}
\hline \multirow{2}{*}{$\begin{array}{l}\text { Номер } \\
\text { сплава }\end{array}$} & \multicolumn{2}{|c|}{ Содержание элемента в сплаве, } & \multicolumn{2}{|c|}{ Фазовые составы сплавов } \\
\hline & Ni, \% мacc. (ат.) & $\mathrm{Si}, \%$ мacc. (ат.) & $\begin{array}{c}\text { По данным } \\
\text { рентгенофазового анализа }\end{array}$ & По диаграмме состояния \\
\hline 1 & $75(59)$ & $25(41)$ & $\mathrm{Ni}_{3} \mathrm{Si}_{2}(100)$ & $\mathrm{Ni}_{3} \mathrm{Si}_{2}(100)$ \\
\hline 2 & $71(54)$ & $29(46)$ & $\begin{array}{l}\mathrm{Ni}_{3} \mathrm{Si}_{2}(30) \\
\mathrm{NiSi}(70)\end{array}$ & $\begin{array}{l}\mathrm{Ni}_{3} \mathrm{Si}_{2}(33) \\
\mathrm{NiSi}(67)\end{array}$ \\
\hline 3 & $67,2(49,2)$ & $32,8(50,8)$ & $\begin{array}{l}\mathrm{NiSi}(96) \\
\mathrm{NiSi}_{2}(4)\end{array}$ & $\begin{array}{l}\mathrm{NiSi}(97) \\
\mathrm{NiSi}_{2}(3)\end{array}$ \\
\hline 4 & $58,3(40)$ & $41,7(60)$ & $\begin{array}{l}\mathrm{NiSi}(34) \\
\mathrm{NiSi}_{2}(66) \\
\end{array}$ & $\begin{array}{l}\mathrm{NiSi}(42) \\
\mathrm{NiSi}_{2}(58)\end{array}$ \\
\hline 5 & $51,2(32,8)$ & $48,8(67,2)$ & $\begin{array}{c}\mathrm{NiSi}(25) \\
\mathrm{NiSi}_{2}+\mathrm{Si}(75)\end{array}$ & $\mathrm{NiSi}_{2}(100)$ \\
\hline 6 & $40(24)$ & $60(76)$ & $\begin{array}{c}\mathrm{NiSi}(8) \\
\mathrm{NiSi}_{2}(57) \\
\mathrm{Si}(35)\end{array}$ & $\begin{array}{l}\mathrm{NiSi}_{2}(79) \\
\mathrm{Si}(21)\end{array}$ \\
\hline 7 & $30(18)$ & $70(82)$ & $\begin{array}{c}\mathrm{NiSi}(1) \\
\mathrm{NiSi}_{2}(49) \\
\mathrm{Si}(50)\end{array}$ & $\begin{array}{l}\mathrm{NiSi}_{2}(59) \\
\mathrm{Si}(41)\end{array}$ \\
\hline
\end{tabular}


казал их хорошее соответствие диаграмме состояния (см. рис. 1). Поскольку сплавы получаются трещиноватыми и не пригодными для механических испытаний, их дробили, усредняли по составу и методом горячего спекания готовили образцы для механических испытаний.

Образцы никелькремниевых сплавов различных составов получали в камере высокого давления с применением реакционной ячейки типа «чечевица» [7]. Реакционную ячейку собирали по схеме, представленной на рис. 2. Спекание порошков сплавов с различным содержанием никеля и кремния проводили следующим образом: реакционную ячейку помещали в камеру высокого давления, проводили нагружение давлением, равным 4 ГПа, производили нагрев до температуры $1400{ }^{\circ} \mathrm{C}$ электрическим током, подводимым к реакционной ячейке. Выдержка осуществлялась в течение 10 с, затем отключали нагрев и снижали давление.

После спекания образцы извлекали, изготавливали шлифы, изучали микроструктуру и определяли микротвердость. Испытание шлифов на микротвердость проводили методом восстановленного отпечатка на приборе ПМТ-3 при нагрузке 2 Н. Результаты измерений микротвердости никелькремниевых сплавов представлены на рис. 3 .

По приведенной на рис. 3 зависимости видно, что с увеличением процентного содержания кремния сначала происходит уменьшение микротвердости. Наименьшее значение микротвердости 5,0 - 6,0 ГПа наблюдается у сплава с 30-40\% Si. Полученные результаты могут быть объяснены особенностями диаграммы состояния $\mathrm{Ni}-\mathrm{Si}$, для которой характерно наличие нескольких химических соединений в интервале концентраций кремния от 15 до $40 \%$.

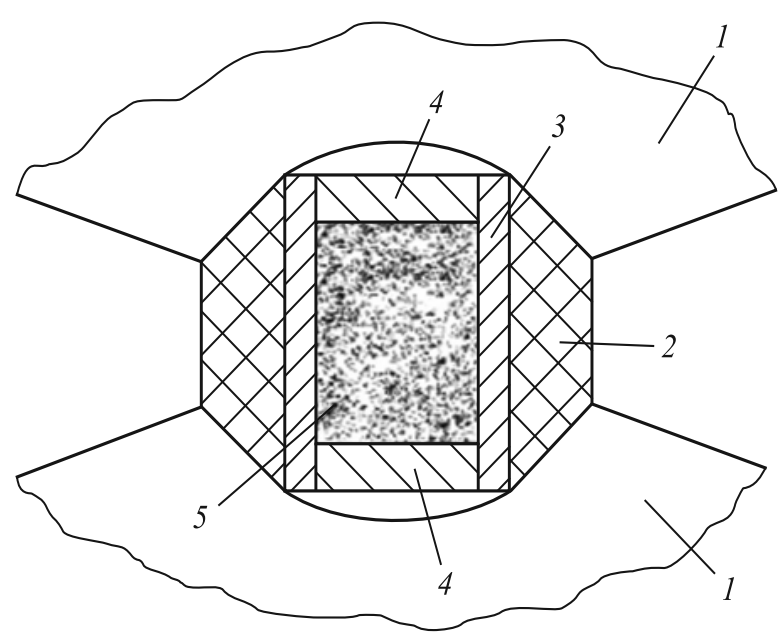

Рис. 2. Схема реакционной ячейки для изготовления образцов никелькремниевых сплавов для механических испытаний:

1 - твердосплавные пуансоны (ВК-6); 2 - контейнер

из литографского камня $\left(\mathrm{CaCO}_{3}\right) ; 3$ - графитовый нагреватель (МГОСЧ); 4 - спрессованные таблетки $\mathrm{BN}_{\text {гекс }}$; 5 - смесь порошков сплавов $\mathrm{Ni}-\mathrm{Si}$
Для микротвердости кремния получено значение 11,3 ГПа, что соответствует данным работы [8], в которой приводится микротвердость кремния вдоль кристаллографического направления (111), равная 11 - 12 ГПа.

Для выявления микроструктуры образцов применяли химическое травление. Для сплавов $1-4$ использовали смесь азотной и соляной кислот (10 мл $\mathrm{HNO}_{3}+$ +30 мл $\mathrm{HCl})$. Для травления сплавов 5- 7 применяли смесь 30 мл $\mathrm{HNO}_{3}+30$ мл $\mathrm{H}_{2} \mathrm{SO}_{4}+10$ мл НF [9]. Фотографии микроструктур, полученные с помощью микроскопа Axiovert 40MАТ при увеличении 200, представлены на рис. 4.

При анализе микроструктуры было обнаружено, что в сплавах 58,2\% $\mathrm{Ni}-41,8 \mathrm{Si}, 40 \% \mathrm{Ni}-60 \% \mathrm{Si}$, $30 \% \mathrm{Ni}-70 \% \mathrm{Si} \mathrm{наблюдается} \mathrm{дендритная} \mathrm{структура.}$ В сплаве 51,2 \% $\mathrm{Ni}$ - 48,8 \% Si присутствуют равноосные зерна интерметаллида $\mathrm{NiSi}_{2}$.

Bbыводы. Разработана технология изготовления никелькремниевых сплавов для проведения механических испытаний, заключающаяся в плавлении сплава под давлением, охлаждении сплава под давлением и снижении давления.

В результате изучения свойств никелькремниевых сплавов установлено, что при увеличении содержания кремния до 30 - 40 \% микротвердость снижается до 5,5 - 6,0 ГПа, при дальнейшем увеличении содержания кремния микротвердость значительно повышается, что связано с появлением в структуре фаз $\mathrm{NiSi}_{2}$ и $\mathrm{Si}$, имеющих высокие значения микротвердости.

\section{БИБЛИОГРАФИЧЕСКИЙ СПИСОК}

1. Jarrige I., De launay R., Jonnard P.// Solid state communications. 2005. No. 136. P. $11-15$.

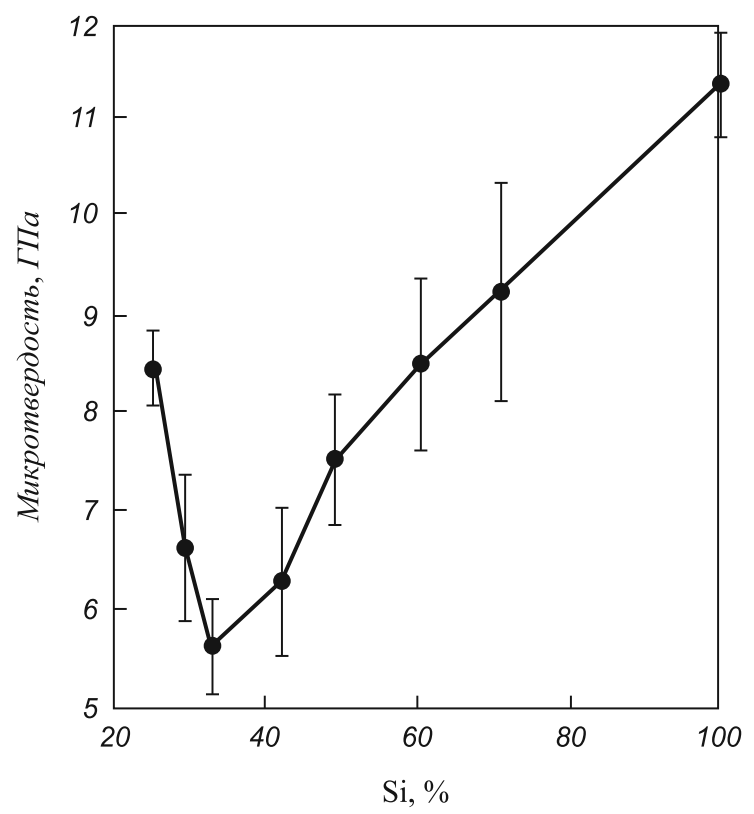

Рис. 3. Зависимость микротвердости никелькремниевых сплавов от их состава (нагрузка $2 \mathrm{H}$ ) 

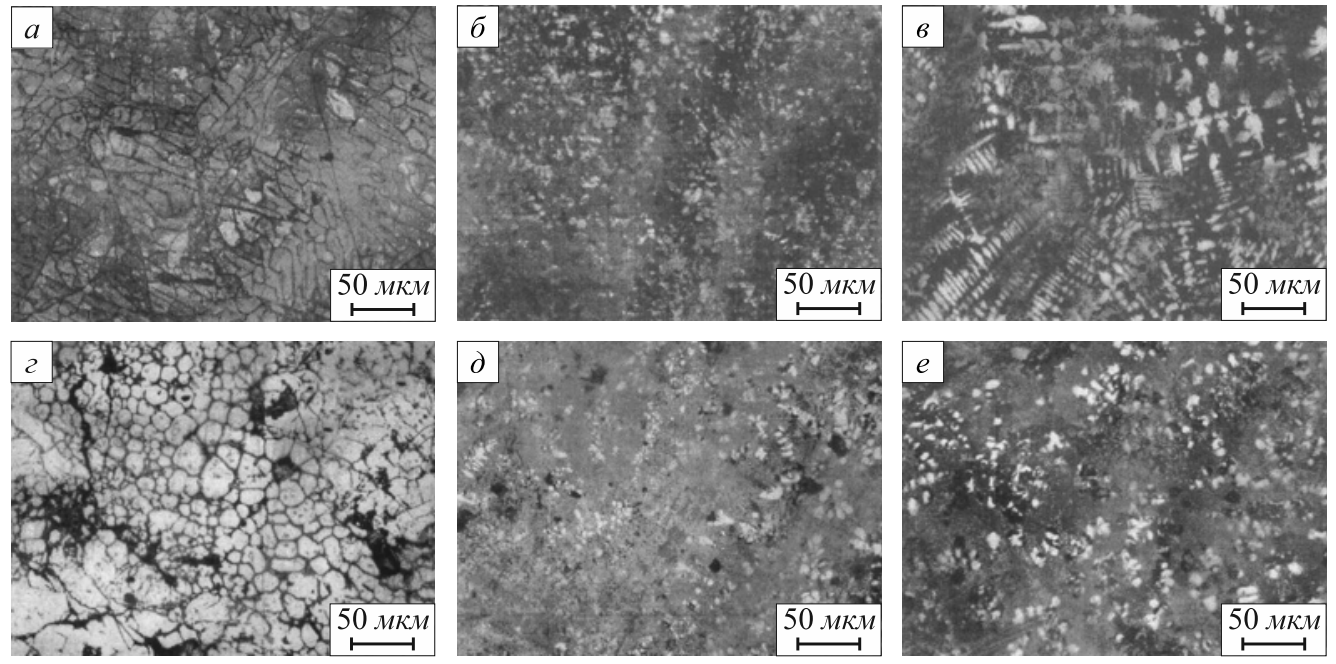

Рис. 4. Микроструктуры образцов сплавов системы никель-кремний с содержанием кремния, \%: $a-25 ; \sigma-29 ; в-41,7 ; 2-48,8 ; \partial-60 ; e-70$

2. Лаптев А.А., С теп а рёв а Н.Н., Полушин Н.И., Бе л о м ы т ц е в М.Ю. // Изв. вуз. Черная металлургия. 2011. № 1 C. $31-36$.

3. Du Y., S chuster J.C. // Metall. Mater. Trans. A. 1999. No. 30. P. $2409-2418$

4. Tokunaga T., Nishio K., Ohtani H., Hasebe M. // Computer Coupling of Diagrams and Thermochemistry. 2003. No. 27. P. $161-168$

5. С амсонов Г.В., Дв орн ин а Л.А., Рудь Б.М. Силициды. - М.: Металлургия, 1979. - 272 с.

6. С а м с о н о в Г.В., В и н н и ц к й И.М. Тугоплавкие соединения: Справ. - М.: Металлургия, 1976. - 500 с.
7. Е лютин А.В., Беломы т е в М.Ю., Лаптев А.А. идр.// Изв. вуз. Порошковая металлургия и функциональные покрытия. 2012. № 4. С. $47-51$.

8. Конце вой Ю.А., Литвинов Ю.М., Фаттахов Э.А. Пластичность и прочность полупроводниковых материалов и структур. - М.: Радио и связь, 1982. -240 с.

9. Ко в ален ко В.С. Металлографические реактивы. - М.: Металлургия, 1981.

(C) 2014 г. А.А. Лаптев, М.Ю. Беломытиев, А.И. Лаптев Поступила 27 марта 2014 г.

\section{MECHANICAL PROPERTIES OF NICKEL-SILICON ALLOYS}

\section{A.A. Laptev, Postgraduate \\ M.Yu. Belomyttsev, Dr. Eng., Professor \\ A.I. Laptev, Leading Researcher}

National University of Science and Technology "MISIS” (MISIS) (Moscow, Russia)

\section{E-MAIL: laptev85@mail.ru}

Abstract. Ni-Si alloys are used in the manufacture of heat-resistant coatings. However, due to the fact that the production of compact specimens presents considerable difficulties are insufficient data in the literature on their mechanical properties. In this work, the manufacturing techniques $\mathrm{Ni}-\mathrm{Si}$ alloys for mechanical testing, which consists in melting the alloy under pressure, cooling the alloy under pressure and pressure drop. Polished sample was made of samples with different chemical composition, their structure and microhardness were studied. As a result, the study found that by increasing silicon content up to $30-40 \%$ microhardness $\mathrm{Ni}-\mathrm{Si}$ alloys decreases to $5.5-6.0 \mathrm{GPa}$, with a further increase in the silicon content microhardness increases significantly, due to the presence of the phase structure $\mathrm{NiSi}_{2}$ and $\mathrm{Si}$, that have high microhardness values.

Keywords: microhardness, microstructure, Ni-Si alloys, polished sample, pressure, melting.

\section{REFERENCES}

1. Jarrige I., De launay R., Jo n nard P. Solid state communications. 2005. № 136.pp. 11-15.
2. Laptev A.A., S te parjova N.N., Polushin N.I., B elomytce v M.Ju. Izvestija vysshih uchebnyh zavedenij. Chernaja metallurgija. 2011. № 1. Pp. $31-36$.

3. $\mathrm{Du}$ Y., $\mathrm{S} \mathrm{chus}$ te $\mathrm{r}$ J.C. Experimental investigation and thermodynamic descriptions of the $\mathrm{Ni}-\mathrm{Si}$ and $\mathrm{C}-\mathrm{Ni}$-Si systems. Metall. Mater. Trans. A. 1999. № 30. Pp. $2409-2418$.

4. Tokunaga T., Nishio K., Ohtani H., Hasebe M. Thermodynamic assessment of the Ni-Si system by incorporating ab initio energetic calculations into the CALPHAD approach. Computer Coupling of Diagrams and Thermochemistry. 2003. № 27. Pp. $161-168$.

5. S a m s o n o v G.V., D v or n in a L.A., R u d'B.M. Silicidy (Silicides). Moscow: Metallurgija, 1979. 272 p.

6. S a m s on ov G.V., Vinn ickij I.M. Tugoplavkie soedinenija: Spravochnik (Refractory compounds: Handbook). Moscow: Metallurgija, 1976. $500 \mathrm{p}$.

7. Eljutin A.V., B elomytcev M.Ju., Laptev A.A.etc. Izv. VUZov. Poroshkovaja metallurgija i funkcional nye pokrytija. 2012. № 4. Pp. 47 - 51.

8. Koncevoj Ju.A., Litvinov Ju.M., Fattahov Je.A. Plastichnost' i prochnost' poluprovodnikovyh materialov i struktur (Ductility and strength of semiconductor materials and structures). Moscow: Radio i svjaz', 1982. 240 p.

9. Kovale n k o V.S. Metallograficheskie reaktivy (Metallographic reagents). Moscow: Metallurgija, 198

Received March 27, 2014 